\title{
How is Fear Constructed? A Narrative Approach to Social Dread in Literature ${ }^{1}$
}

\author{
KAIRI JETS
}

\begin{abstract}
Fear-inducing narratives can be divided into two subtypes of horror and dread. While horror stories concentrate on a concrete visible object such as a monster, in dread narratives the object of fear is abstract or absent altogether. Pure forms of either are rare and most narratives mix both types, usually with dominant in one or the other. An interesting subtype of dread narratives is the narrative of social dread, where the fear is social in nature.

One of the few narratologists to study construction of fear in arts, Yvonne Leffler suggests a variety of narrative techniques often used in horror fiction. Adjusting Leffler's list of techniques for tales of dread instead of horror helps analysing the nature and amount of dread present in a range of different narratives from light reading and literary fiction to non-fiction. A narrative approach helps to reveal how non-fiction texts use similar techniques, and sometimes more extensively than fictional texts. Lionel Shriver's We Need to Talk About Kevin (2003) is an excellent example of social dread in fiction, where societal failures are a big part of the fears induced, and the questions raised in the narrative are denied definite answers. Kanae Minato's Confessions (2008) is closer to a thriller, because despite raising issues of societal failure, the work gives conclusive answers to all of the questions raised during the narrative. Although Haruki Murakami's Underground (1997-98) is a nonfiction compiled from interviews of terror attack survivors, it nevertheless has the hallmarks of a social dread narrative, such as question-answer structure and abstractness of the source of fear. More importantly, Murakami's work alternates between identifying and anticipatory readings, gives no definitive answers to the questions it poses, and the fear it conveys is social in nature.
\end{abstract}

Keywords: narratology; dread; horror; social; literary theory

1 This study was supported by the Estonian Research Council (Grant PUT1481) and by the European Union Regional Development Fund (Center of Excellence in Estonian Studies). 
JETS

\section{Introduction}

Terrorism, fear of crime and of violence keep the levels of anxiety high and doubt in the possibility of truth is growing despite the $21^{\text {st }}$ century being the era of unparalleled safety and access to information. It is more important than ever to look at the way we tell stories and construct fear in different narratives. Narratives that involve a more abstract or intangible source of fear (dread) are significantly less researched than those with a tangible source of fear (horror), and even fewer look at the narrative tools used to make those narratives work. Narratology gives us an objective way to look at different texts and analyse them as equals. This article will adjust narratologist Yvonne Leffler's findings on common narrative characteristics of horror stories to fit dread narratives, and analyse the elements of dread, especially their social aspects. The works analysed are Lionel Shriver's novel We Need to Talk About Kevin, Kanae Minato's thriller Confessions, and Haruki Murakami's Underground, a non-fictional account of the sarin gas attack in Tokyo subway on 20 March 1995. Those specific texts were selected to demonstrate varying levels of dread in texts as different as bestselling thrillers, literary fiction, and catastrophe historiography. I will analyse the structure of those texts; look at how and to what extent anticipation and identification is constructed, and lastly analyse the depiction of adversaries and threats, paying special attention to their social aspects.

\section{Horror and dread}

Although the main focus of researching fear narratives has been on horror stories, several scholars have distinguished a different type of fear narrative that Ann Radcliffe, the first to do so, called "terror" (Radcliffe 1826: 149), Noël Carroll "art-dread" (Carroll 2004: 42) and Matt Hills "Lovecraftian aesthetics" (Hills 2003: 141). Still, Radcliffe left her theory unfinished and rather vague, Carroll defined the term but never studied it further, and Hills saw it as a mere aesthetics that need not be defined as a genre of its own right so we would not stray from ordinary language attributions. There are others, who have dealt with the topic on a less thorough or more essayistic way (namely practitioners H. P. Lovecraft and Stephen King, see Lovecraft 2018, King 1981), but for framing the history of academic study of forms of horror, these three are essential. In this article I define dread narratives as a distinct subtype of fear narratives that either on purpose or accidentally employ specific narrative strategies to create ambiguous feelings of unease and anxiety in the audience. Unlike the other subtype horror narratives, dread narratives do not have a concrete object that arouses fear. Rather, as Carroll puts it: 
$[t]$ he uncanny event which tops off such stories causes a sense of unease and awe, perhaps of momentary anxiety and foreboding. These events are constructed to move the audience rhetorically to the point that one entertains the idea that unavowed, unknown, and perhaps concealed and inexplicable forces rule the universe. Where art-horror involves disgust as a central feature, what might be called art-dread does not. (Carroll 2004: 42)

The strategies of fear elicitation for horror and dread can and often do converge in a single work in very different ways, or as Carroll puts it: "the admixture may take a range of forms in different stories" (ibid.).

In a sizable part of dread narratives, the uncertainty and vagueness are connected to social categories or beliefs, because much of what is intangible is also supra-individual and social. Some examples of social dread are a country's repressions against its citizens seen from the point of view of victims, depiction of the social aspects of a serious crime or an epidemic, or inadequate response of emergency services in the case of a catastrophe. The elements of social dread can be found from a range of artworks from holocaust memoirs and highquality fiction to formulaic crime fiction and thrillers. The amount of dread may vary from work to work, and it does not depend on their genre, but rather the characteristics of the work itself, and the life experiences of the audience.

\section{The narratological approach}

In Horror as Pleasure: The Aesthetics of Horror Fiction Yvonne Leffler points out main characteristics of horror narratives - question and answer structure (also interrogative or erotetic structure, or structure of mystery), a special depiction of the adversary, and emotive narrative technique which manifests in identification and anticipation (Leffler 2000: 95). Leffler sees horror as a more complex subtype of thriller (ibid. 112), the purpose of which is to put the audience in the "state of expectant uncertainty" so unlike thriller, the purpose is to hide not reveal the solution, so the answers to the questions are not clear or even relevant (ibid. 113). The distinction of objective events and subjective experience disappears through changing the order of the events (ibid.), focusing on the subjective experience of the character(s) (ibid. 124-125), and changing or restricting the focalization. (ibid. 136).

Leffler's second important characteristic of horror stories is the emotive narrative technique, or alternating between identifying and anticipatory readings (ibid. 165-166). Identifying reading means engaging the audience on an emotional level by displaying the events from the subjective point of view of a positive main character, and creating empathy toward them (ibid. 166-177). 
JETS

Anticipatory reading means that based on genre conventions, hints in the story and its atmosphere, the audience is lead to objectively predict an unpleasant outcome for the main character (ibid. 177-182). In other words, emotive narrative technique makes us care and fear for the main character more than other variations of thriller would. I would add extra-textual knowledge as an aspect of anticipatory reading, which is especially relevant when it comes to non-fictional narratives, but does function in fictional narratives as well.

The narrative techniques Leffler considers necessary to depict the concrete horror adversary must be reconsidered keeping in mind the abstract and intangible threat in dread stories, but some aspects of Leffler's research about the adversary can still be used without much adjustment. Namely, that the threat to the positive main character must be real and considerable (ibid. 137), it should embody for both the character and the audience the unknown Other, but also a mystery and a temptation (ibid. 139-140), and threat to the identity of the main character (ibid. 153). However, all techniques connected to the physical attributes of the adversary in Leffler's theory become irrelevant, and additional characteristics become necessary. These are threats to the main characters worldview and well-being, and the threat to audience's worldview, in other words something that threatens to disturb drastically their view of the workings and safety of the world order. When it comes to social dread, the difference lies only in the social nature of the threat. The source of fear is the faulty operation or even disintegration of human relationships or society, such as dysfunctional family relations, panic resulting from terrorist attacks, or government's failures to respond adequately to emergencies.

The first part of this article described Leffler's theory on characteristics of suspense and horror, and noted additional aspects relevant to dread specifically. The presence of question-answer structure implies the general genre of thriller, and the ambiguity or irrelevance of the answers, obfuscation of the difference between subjective experience and objective events, and emotive narrative technique point more specifically to fear narratives (both horror and dread). A physical concrete adversary with specific properties signifies a horror story, while an abstract creature, a situation or an event that physically or psychologically threatens the positive main character, their wellbeing, worldview, or the worldview of the audience is characteristic of the dread story. I will now use those findings to analyse three very different texts, and show the extent and nature of dread in those narratives. 


\section{Lionel Shriver's We Need to Talk About Kevin}

Lionel Shriver's novel We Need to Talk About Kevin (hereafter AK), first published in 2003, depicts the childhood and development of the school shooter Kevin from the point of view of his mother Eva. The novel seems to be a thriller at first sight, but analysing it further reveals two possible interpretations of the events. Because of the structure of the narrative, the audience is encouraged to believe the narrator's account of the events, but the further the novel progresses, the more strongly an alternative interpretation suggests itself. AK is thus a good example of structural dread in fiction, with implications of overstepping the social norm in either interpretation marking its type of dread as social.

Shriver's novel takes the form of Eva's letters to her husband Franklin and starts with the couple's romance, contemplations of having children, and Eva's sense of disconnect with Kevin from the first minutes he is born. The order of events is not strictly chronological, instead subjective memories connected by associations are divided into letters of relatively equal length, and in general move toward Thursday (the day of the shooting). Eva's story is her interpretation of events, and the audience can only rely on the words of a possibly unreliable narrator to construct what really happened. Her limited point of view and the descriptions of subjective experience of fear blur the line between objective events and subjective experience that, Leffler suggests (Leffler 2000: 125-136), is characteristic of fear narratives.

Shriver's novel does use the question-answer structure to some extent, as the audience knows from the start that Kevin is a school shooter, but they do not know what exactly happened to him and with Eva's marriage to Franklin. The ending of the novel clearly answers the question about marriage, and would thus classify the work as a thriller (all questions answered, no ambiguity), but the answer to the question about the real villain of the story remains ambiguous and leaves open the possibility to the work's interpretation as a fear narrative. That double interpretation of "Kevin as the monster" versus "Eva as the monster" makes analysing identifying reading in Shriver's novel somewhat difficult, because the sympathy and compassion towards the main character becomes problematic at least half of the time. Even if the audience sees Kevin as the more positive of the two characters, the first-person narrator Eva supplies all the subjective experiences of fear, and the audience needs to work hard to reinterpret the story themselves. It is also important to note that such a reinterpretation can only occur at the end of first reading and thereafter.

The first interpretation of "Kevin as the monster" involves no physical threat from Kevin to Eva, but there is the psychological threat of manipulating the people around her, especially Franklin. By presenting a physical threat to 
JETS

Eva's loved ones, Kevin does endanger her well-being and sense of security. Although Kevin himself is by no means abstract, the danger he presents to Eva could be seen as abstract, since he only damages her indirectly. Kevin as a threat reflects Eva's inner state, because she only wanted to have a child to have at least a part of Franklin to keep to herself (Shriver 2011: 59), but instead lost him to Kevin - at first by gradually losing Franklin's trust, and then by losing him to death. Kevin exists because of Eva's fear and is at the same time its actualizer. Kevin threatens the worldview of the audience by implying that a child could be born evil, that school shooters are raised in completely ordinary-looking families and cannot be detected before they commit the act, and by activating knowledge and fears about similar shootings in the extra-textual world.

The second interpretation of "Eva as the monster" sees Eva as a physical threat to Kevin evident in her breaking his arm (Shriver 2011: 229), and a psychological threat by way of constant distancing. Eva's disassociation from Kevin threatens his well-being and lets him grow up without a sense of security and having a distorted worldview. Eva as the adversary is not an abstract being, but the danger she poses to a sympathetic character Kevin is vague and prolonged, and the possibility of Eva as the unreliable narrator adds to the atmosphere of unease. The danger to the worldview of the audience comes from the realizations first, that in a seemingly ordinary family a mother can torture her son and turn him into a criminal, and second, that the audience has been manipulated to feel sorry for the monster instead of the victim for the most of the story. This interpretation activates the audience's extra-textual knowledge of various cases of domestic and child abuse, and possible fears connected to it.

The feeling of fear in Shriver's novel very often comes from the social factors, and both possible interpretations focus on the dysfunction of familial bonds. The "Kevin as monster" approach activates the societal fears concerning school shootings, while the "Eva as monster" approach focuses more on the parental violence and activates the societal fears around neglect and raising a child. Much of the dread in the novel comes from the simultaneity of two alternative interpretations, because there is no reason to prefer one to the other, so the audience remains in a state of uncertainty.

AK contains several elements of dread the more prominent of which are in its structure. The events are portrayed through a subjective point of view; the answer to the question about the reliability of the narrator is inconclusive and conjures up fear in the audience because of its vagueness and abstractness. The story alternates between identifying reading that sees events from the point of view of the character, and the anticipatory reading that uses hints in the story and its atmosphere to refer to the unfortunate fate of the main character. In both interpretations the threat is mostly psychological, but the interpretation 
of "Kevin as monster" activates the extra-textual knowledge about school shootings, while the interpretation "Eva as monster", focuses on the extratextual knowledge about domestic violence and only activates after the first reading. Much of the dread in the novel comes from the simultaneity of the two interpretations and the insecurities of the audience in choosing between them. That insecurity comes from the fact that since either of the two excludes the other, only one of them can be true.

\section{Kanae Minato's Confessions}

Kanae Minato's novel Confessions (Kokuhaku, first published 2008; in English $2014)^{2}$ takes the form of several first-person narratives from various perspectives. It starts with the confession by the homeroom teacher Moriguchi that she has added the blood of an HIV-carrier to the drinks of two students (A and B) as a revenge for killing her daughter, because in her opinion underage criminals in Japan receive too lenient sentences. The novel proceeds to describe the spurning of the said students by their classmates, B going insane, A's attempt to find her mother and blow up his school, and ends with the teacher Moriguchi's final account of her revenge. Unlike AK, Confessions is much closer to a thriller or crime story than to a fear narrative in its structure as well as character building. Minato produces a neat story without much ambivalence, even when its premise suggests a novel about twice as dreadful as Shriver's.

Minato's Confessions uses the question-answer structure as expected from a thriller, but unlike fear narratives and Shriver's novel, the answers to the questions are extant and unambiguous, so by the end of the work the audience knows exactly who did what how, where and why. The purpose of the narrative structure is not to leave unanswered questions, or raise permanent doubts in the audience about the events, characters or other details, but to create suspense that leads the audience forward in the story. All the contradictions are explained satisfactorily by the end of the story and all of the suspense ended. Confessions uses limited viewpoints of the characters and conveys their subjective fear experience to some extent, but by explaining away all contradictions between different voices, the novel does not blur the line between objective facts and subjective experience, unlike AK. The order of the events is changed minimally, only to make transitions of the viewpoint smoother, so each new narrator gives an overview of the events up to that point as they see them, and then proceeds with descriptions of some new events.

2 Translated by Stephen Snyder. 
JETS

Identifying reading in Confessions does not work the way it should in a fear narrative, because there is no positive main character. Nothing in the text conjures deeper sympathy for any one character, so the events seem merely the logical outcome of a tragic collision between characters with understandable motives. Anticipation is mainly created through the structure where the slight inconsistencies between different narrators' accounts create a general anticipation for the continuation of the story, but because of the failure of identifying reading it does not develop into a concern for the wellbeing of a certain character. The genre conventions and some hints in the story allude to the unfortunate fate of the characters, but using direct discourse leaves little room for the creation of atmosphere and more hints in the story. Like AK, the novel does not depict any historical events, so no extra-textual knowledge can point to a character's unfortunate fate and thus create anticipation.

Since Confessions gives the reader both sides of the story, the villain can be either the students A and B, or the teacher. Students A and B as adversaries do not threaten the teacher Moriguchi physically, but through harming her daughter they do pose a threat to her wellbeing and psyche. The students are neither abstract nor unknown to the teacher, but for the audience aware of Japanese social issues the adversaries' youth activates extra-textual knowledge and fears about real incidents involving underage criminals getting lenient sentences for horrible crimes.

The teacher Moriguchi as the adversary threatens her two students physically (contagion with HIV), psychologically (they are spurned by their classmates), their wellbeing (the fate of student B and both students' mothers) and to some extent their sense of security (the lack of the sense of security is what drives student B mad). The audience's sense of security is threatened by the topic of wilful contagion with HIV and the thought of the danger a teacher could pose to her students, but might be increased by underage criminals being punished for their crimes. Like with the previous interpretation, the teacher is not abstract nor unknown to her students, but since the way she endangers them is indirect, she is more abstract than the student adversaries.

The ending exposes both parties as psychopathic and the audience as complicit to whichever side we chose to identify with. Like in AK, we tentatively accept the story of the teacher (mother), because she is the first to tell it. The following narrators describe the students' situation and behaviour after the teacher's confession, thereby giving another slant to the events, but much more directly than what happens by the end of Shriver's novel. Student A displays in his story a fateful weakness of desperately longing for his mother and becomes almost sympathetic. The last narrator Moriguchi then reveals that she has turned student A's plan against him by having him inadvertently destroy the only thing in the world that mattered to him. 
One of the justifications of the teacher's revenge is the relative lenience of the Japanese legal system towards young criminals; she refers to an actual double murder in Kōbe in 1997. The second incident (Minato 2014: 25) is the invention of the author but bears many similarities to other juvenile crimes that have shocked Japan in the last decades. For an informed audience, the mere mention of juvenile crime, similarly to school shootings in Shriver's novel, activates the fear of child psychopaths who can attack at any given time without facing serious consequences. The other type of social dread central to Minato's work concerns the fear of contagion and impurities, more specifically being infected with HIV. Although the HIV-positive diagnosis no longer means the death sentence, the fear and stigma of previous decades lingers. A part of that way of thinking is carried by folklore and societal reaction (see Rushing 1995), a part by more archaic and general conceptions of contamination as quite famously discussed by Mary Douglas (see Douglas 1966). The act of intentional infection activates the audience's prior extra-textual fears and anxieties concerning contamination, which then keep working in the background as the plot unfolds. Shriver's novel contemplating the possibility of an innocent child being "contaminated" by the rejection of his mother is a variation of the same theme.

Very much like AK, Confessions raises the question of the mother's share of blame in their children's crimes by having both guilty students have dysfunctional relationships with their mothers. Student B's mother is overprotective and sees no fault in her son's actions, while student $\mathrm{A}$ has an extreme obsession with his mother who left her family to pursue a brilliant career in science. Less obvious is whether Moriguchi is being blamed for her child's death, although some characters mention that her carelessness was the reason for her child's death. Like in Shriver's work, the anxieties surrounding motherhood come into play, but Minato seems less ambivalent about the suggestion of guilt than Shriver does. Where Shriver sows doubt, Minato points fingers by the omission of any alternative.

When AK is a choice between two plausible interpretations, then in Confessions both interpretations are true at the same time with no contradictions between them. That is because Shriver's novel uses one possibly unreliable narrator while Minato matches all the different accounts in her novel perfectly together so there is no reason to question the veracity of anything. There may be moral questions about the teacher's behaviour and its proportion to the crime but not to the "how" or "why" of anything that happens. This places Confessions closer to the thriller category where the answers make perfect sense in the end, with some elements of dread such as the changing adversary, the possible complicity of the audience, and activation of social fears surrounding juvenile crime, HIV and motherhood. While ambivalence in interpreting morals and 
JETS

addressing topics of social dread could classify Confessions as a dread narrative, the lack of differentiation between actual events and subjective truths, and the lack of a positive central character positions the novel as a hybrid of the thriller and the dread narrative where characteristics of the former dominate over those of the latter.

\section{Haruki Murakami's Underground}

Haruki Murakami based his work Underground (Andāguraundo, first published 1997-98; in English 2000)3 ${ }^{3}$ on his interviews about the 1995 sarin gas attack in Tokyo subway. At first glance Underground does not seem a good candidate for a dread narrative, because it depicts a real-life tragedy respectfully without trying to sensationalize it in any way. Upon closer inspection, Underground reveals more traits of dread than either AK or Confessions. Its structure, the way it builds empathy and anticipation, and the abstract nature of the adversaries clearly demonstrates a strong dominant of dread.

The first part of Murakami's work is called Underground, and consists of seven subsections corresponding to the locations of the attack, each of them with a prologue describing the facts of the event. Each subsection continues with victim interviews, who give a short account of their background, systemic and detailed descriptions of the fateful day, their injuries, and attitude toward Aum Shinrikyo ${ }^{4}$ at the time of the interview. The interviews are coherent texts with a very similar structure and very few actual questions from Murakami, but the author describes in the preface how the interviews lasted for hours and the resulting texts were negotiated to get the approval of the interviewees. Thus, the texts are not so much interviews as testimonies structured by Murakami. The first part ends with an afterword called Blind Nightmare: Where Are We Japanese Going?. The second part of Murakami's work titled The Place That Was Promised consists of a preface, an afterword and interviews with Aum members with a similar structure to the stories as the first part, but with more questions and interruptions from the author. They start with the cultists' childhood, background and reasons for joining Aum, continue with their life as a member, thoughts about individuality, Aum and its leader, and end with descriptions of their life after the attack.

Translated by Alfred Birnbaum and Philip Gabriel.

4 Oumu Shinrikyō, hereafter Aum is a Buddhist cult established in Japan in 1984 by Shōkō Asahara. The cult planted packets of sarin gas in Tokyo underground on 20 March 1995, killing 12 and severely injuring 50 people. 
Underground is a description of a historical catastrophe and, unlike previous two works analysed in this article, the purpose of its structure is not to hide a solution to the puzzle but to answer the question posited by the author. The different intentions of the authors do not change the fact that thrillers and historiographic narratives are quests for knowledge, both of these narratives progress through the gradual answering of various questions heading towards greater knowledge. Some authors, such as Minato, present their findings as indubitable truth of what happened and why, while others, such as Shriver and Murakami, either do not come to a clear conclusion, or let the facts or victims speak for themselves. The authors' unwillingness to declare their findings an indubitable truth can regardless of their intent cause unease and a sense of dread in the audience. The historiographic works that let the victims speak for themselves with minimal interpretation, obscure the line between objective events and subjective experience just like the fear fictions. Underground is an excellent example to this. Although the narrative is ordered chronologically, the focus is on the subjective experience of the victim, and inconsistencies are left intact. The focalization keeps shifting between tens of victims and their loved ones, who describe their experience of the event including what they thought or felt at the time.

Underground has not been seen as a thriller, narrative of horror or dread, but it does have considerable similarities to those categories. The questionanswer structure where the answers are not clear, and conveying the events from several focalizations that portray the subjective fear experience of a sympathetic individual create the sense of horror and dread in the audience. Like "Confessions", it offers several views about the central event, and we see the focalizers' emotional experience, but because in Murakami's work the focalizers are sympathetic, then Leffler's emotive narrative technique (Leffler 2000: 165-195) functions in Underground. Both Underground and AK provide two sides of the story, but unlike AK, Underground fully supplies the second interpretation, not leaving it to the imagination of the audience. In addition, the two interpretations do not exclude each other (Eva as monster vs Kevin as monster), but allow for a composite interpretation, where both sides are identifiably human and thus sympathetic even if not entirely correct in their conduct or opinions. Murakami's tactic of not interviewing the actual perpetrators creates a third party to the opposition of victims and society versus Aum. Both interviewed groups oppose themselves to the higher echelons of Aum, and that allows the audience to blame the leaders of Aum of all the crimes in question.

The adversary in the historic catastrophe narratives can vary from abstract natural disasters like the Great East Japan Earthquake of 2011 to concrete perpetrators such as the terrorists of the Tokyo sarin attack. The feelings they 
JETS

evoke in the audience can thus significantly differ on the horror-dread scale, but more important than the actual nature of the adversary is the way the author portrays them. Even existing human beings can be portrayed as almost omnipotent monsters, who seem otherworldly and leave the victims, the author and the audience powerless. The adversaries in Underground are tangible, but since none of the victims interviewed in the first half nor Murakami himself had any direct contact with them, and attitudes toward them vary a lot, the perpetrators are vague even though not intentionally composed by the author to evoke a sense of dread or horror. In the second part of Underground, the main adversary is the cult leader Shōkō Asahara following whose instructions the attack was carried out. Even though Asahara was a tangible person, even the most factual descriptions make him seem like an exceptional man with a supernatural knack for influencing people. When the first part of Underground focuses on the attack itself, then the second part examines Asahara and the phenomenon of Aum. The evoker of dread in the first part is uncertainty about one's safety, in the second part, it is the sinister and almost otherworldly figure of Asahara, the astonishing daily life of the cult, and the part Japanese society played in the formation and success of Aum.

The dread in historic catastrophe narratives is often, even if not always, social in nature. In stories about natural disasters, the fear comes from the breakdown of society and failures in its essential functions. Stories about terrorism and other manmade disasters add to that doubts in human nature and conflicts with the worldview. In addition, the extra-textual knowledge is often social in nature, for example in the number of people involved, or aftereffects for the society. Most notable among these stories are those about the terror attacks, because in addition to the physical victims, the secondary and from the point of view of the perpetrators perhaps the more important target is the society they meant to terrorize. In fictions, extra-textual knowledge may or may not affect the construction of dread, but even if it does, the amount of dread created is smaller than in historiographical texts.

The social dread in the first part comes from the significant failure of society to keep its citizens safe, such as problems with public services, emergency services and hospital system. The Tokyo subway employees were unprepared to deal with poisonous substances, the ambulances did not arrive in time to the correct location, and the number of calls received overwhelmed the phone lines of emergency services. Furthermore, the immediate medical help given was incorrect or insufficient, and there were no mechanisms of psychological aid at the time of the event or the interviews. In addition, several victims pointed out the difference between the event itself and how it was portrayed in the media, for example the description by Masanori Okuyama: 
When I was out in front of Kodemmacho Station, certainly that one block was in an abnormal state, but all around us the world carried on the same as ever. Cars were going by. Thinking back over it now, it was eerie. The contrast was just so weird. But on television they only showed the abnormal part, quite different from the actual impression I had. It just made me realize all the more how frightening television is. (Murakami 2003: 134)

In the second part of Underground the social dread comes from the crazy guru's capability of brainwashing, or alternatively, the malleability of human mind. One by one, the members of Aum tell the story of joining the organization where, although their perception of Asahara and the attacks is very different, there are some distinct similarities in their reasons for joining Aum. They have all been doubtful about or incompatible with Japanese society. The cause is often depression or other treatable mental health problems that were left unaddressed because of social stigma or ignorance. The same goes for sufferers of excessive stress, social pressure or posttraumatic stress disorder. The culprit creating the need for Aum was the rigidity of Japanese society, and Murakami does point that out in his afterword.

Another aspect of social dread in the second part of Underground is the ease with which people went along with the deepening madness of Aum. The former Aum member Hajime Masutani describes the Stockholm syndrome of some members tortured by various methods of "training” who are still in Aum: „They'd suffer, be taken to the edge of death, and then be kindly told "You did well". And they'd think "I was able to overcome the trials given to me. Thank you, O Guru!"” (ibid. 256) Several of the interviews address the topic of Self of Aum members; Hidetoshi Takahashi notes that in an organization like Aum, the Self is constantly under attack and deteriorates: " $\mathrm{t}$ ] hings are forced on you from above and you're continually attacked for not accepting the status quo, not being devoted enough, and inevitably your spirit is broken" (ibid. 302).

In conclusion, although the main objective of Underground is not to evoke dread in the audience but to inform, its structure and alternation between identifying and anticipatory readings, and manipulation with the audience similar to the fictional texts does point to a dread narrative. The description of the adversary in Underground is twofold. In part one, the dread comes from the physical danger caused by a sudden and initially unseen event and failures in some aspects of society. In part two, dread comes from the half-mythological descriptions of Shōkō Asahara and Japanese society's complicity in the creation and prosperity of an organization like Aum. Because of sympathetic focalizers and focusing on the subjective feelings over the objective facts, Underground functions more like a dread narrative than either AK or Confessions. 
JETS

\title{
Conclusion
}

Using the narrative tools outlined by Yvonne Leffler to analyse potential dread narratives gives unexpected results. Elements of dread, including social dread, exist in surprising quantities in very different types of narratives from thrillers to catastrophe historiographies. Considering analysed texts dread narratives or narratives with elements of dread is entirely justified, even though the exact amount and nature of the dread varies significantly. Confessions, which seemingly had the most potential to be a dreadful tale of revenge, had the least amount of dread, while Murakami's historiography had the strongest indications of dread despite its genre suggesting otherwise. Shriver's novel was the middle ground between the others in terms of both expectations and findings. Instead of a depiction of a dreadful deed and its foreshadowing, it gives a complex picture of blame and social anxieties, where the correct answer is anybody's guess.

Leffler's suggestion concerning signifiers of fear narratives can give us tools for analysing very different texts - the question and answer structure with ambivalent answers, and efficient use of empathy and anticipation suggests the predominance of the fear narrative. The nature of the adversary - a concrete horror villain, or an ambivalent dread threat - leads us to either horror or dread respectively. Rather than pinpointing a genre, the results give an insight into the work analysed, and help compare it to other texts. Rather than a genre of dread, we can thus speak of a dominant of dread (or of thriller or horror) instead.

The narratological nature of this approach enables an analysis of very different types of texts from literary fiction to historiography, but its application to other media such as films or video games needs further research. Visual media use different tools to achieve empathy and anticipation, and to convey the nature of the adversary, but the purpose of these tools is the same as in textual narratives. One further avenue of research includes analysing the construction of dread in television news programs to reveal how they knowingly or unknowingly construct stories of fear.

\author{
Kairi Jets \\ kairi.jets@gmail.com \\ c/o Interlitteraria \\ Ülikooli 16-113 \\ 51003 Tartu \\ EESTI / ESTONIA
}


How is Fear Constructed?

\section{Works cited}

Carroll, N. 2004. Philosophy of Horror or Paradoxes of the Heart. New York; London: Routledge.

Douglas, M. 1966. Purity and Danger: An Analysis of Concepts of Pollution and Taboo. Routledge \& Kegan Paul Limited, London.

Hills, M. 2003. An Event-Based Definition of Art-Horror. - S.J. Schneider, D. Shaw, eds., Dark Thoughts: Philosophical Reflections on Cinematic Horror. Lanham, MD: Scarecrow Press, 138-157.

King, S. 1981. Danse Macabre. Everest House.

Leffler, Y. 2000. Horror as Pleasure: The Aesthetics of Horror Fiction. Stockholm: Almqvist \& Wiksell International.

Lovecraft, H.P. 2018. Supernatural Horror in Literature. http://www.hplovecraft.com/ writings/texts/essays/shil.aspx, (28.08.2018)

Minato, K. 2014. Confessions. New York: Mulholland Books.

Murakami, H. 2003. Underground. The Tokyo Gas Attack and the Japanese Psyche. London: Vintage Books.

Radcliffe, A. 1826. On the Supernatural in Poetry. - The New Monthly Magazine and Literary Journal, 1, 145-152.

Rushing, W.A. 1995. The AIDS epidemic: social dimensions of an infectious disease. Boulder, Colorado: Westview Press.

Shriver, L. 2011. We Need to Talk About Kevin. London: Serpent's Tail. 